\title{
Custos de produção e rentabilidade econômica do cultivo da mandioca em Goiás
}

\section{Production costs analysis and economic profitability of cultivation of cassava in Goias, Brazil}

\author{
Francielle Wanderley Ribeiro ${ }^{1 *}$, Carolina Candida Rodrigues ${ }^{2}$, Matheus da Silva Araújo ${ }^{3}$, Andrécia \\ Cósmem da Silva ${ }^{4}$, Fábio Santos Matos ${ }^{5}$
}

${ }^{1}$ Graduanda em Agronomia, Universidade Estadual de Goiás, Campus Ipameri, fran3wanderley@ gmail.com; ${ }^{2}$ Graduanda em Agronomia, Universidade Estadual de Goiás, Campus Ipameri, carolagro28@gmail.com; ${ }^{3}$ Doutorando em Solos e Nutrição de Plantas, Universidade de São Paulo, Campus Piracicaba, araujomatheus@usp.br; ${ }^{4}$ Professora e Mestre da Universidade Estadual de Goiás, Campus Ipameri, andreciacs@hotmail.com; ${ }^{5}$ Professor e Pós-Doutor da Universidade Estadual de Goiás, Campus Ipameri, fabio.matos@ueg.br.

\section{A R T I G O}

Recebido: $12 / 09 / 2018$

Aprovado: 16/12/2018

Palavras-chave:
Agricultura familiar
Grandes culturas
Manihot esculenta
Viabilidade econômica.

Key words:

Family agriculture

Field crops;

Manihot esculenta

Economic feasibility.

\section{R E S U M O}

A mandioca destaca-se na economia brasileira por ser cultivada em diversas regiões, devido à tolerância a diversas condições edafoclimáticas. No entanto, para que seja conduzida de forma eficaz em uma propriedade, é necessário que sejam elaboradas estimativas de custos para a tomada de decisão, principalmente na região sudeste de Goiás onde o cultivo da espécie é realizado muitas vezes de modo empírico. Com isso, o objetivo deste trabalho foi realizar o levantamento dos custos de produção e determinar a viabilidade econômica da implantação da cultura da mandioca através de indicadores econômicos. Para isso realizouse o estudo da viabilidade econômica por meio dos seguintes indicadores: Receita Bruta (RB), Taxa Interna de Retorno (TIR), Valor Presente Líquido (VPL), Índice Benefício Custo (IBC) e Payback atualizado. Realizou-se a análise de sensibilidade, de modo a projetar cenários que possam contextualizar uma situação real. A análise de viabilidade foi realizada com taxa de 6,6\% a.a., em um horizonte de cinco anos. Os valores obtidos foram; $\mathrm{RB}=\mathrm{R} \$ 10.350,00, \mathrm{TIR}=45 \%, \mathrm{VPL}=\mathrm{R} \$ 49.268,45, \mathrm{IBC}=1,37$ e Payback atualizado $=$ segundo ano. A análise de sensibilidade mostrou que a oscilação entre $+10 \%$ e $-10 \%$, não tornou o projeto inviável, assegurando o retorno do capital investido no empreendimento, exceto quando esses são realizados simultaneamente, tornando os resultados inviáveis. De acordo com as condições de estudo conclui-se que, o projeto é economicamente viável e o cultivo da mandioca se destaca como uma boa alternativa na prática de diversificação econômica na produção da propriedade rural.

\section{A B S T R A C T}

Cassava stands out in the brazilian economy because it is grown in several regions, due to tolerance to diverse soil and climate conditions. To be conducted effectively a property must be prepared cost estimates for decision-making, especially in the Southeast region of Goiás, where the cultivation of species is performed empirically. Therefore, the objective of this work was to survey the production costs and to determine the economic viability of the implantation of the cassava crop through economic indicators. For this purpose, the economic viability study was carried out using the following indicators: Gross Revenue (RB), Internal Rate of Return (IRR), Net Present Value (NPV), Cost Benefit Index (IBC) and Payback updated. Sensitivity analysis was carried out in order to design scenarios that could contextualize a real situation. The feasibility analysis was carried out with a rate of $6.6 \%$ pa, in a 5-year horizon, $\mathrm{RB}=\mathrm{R} \$ 10,350.00, \mathrm{IRR}=45 \%, \mathrm{NPV}=\mathrm{R} \$ 49,268.45$, IBC $=1.37$ and Payback updated $=$ second year. In the sensitivity analysis it was shown that the oscillation between $+10 \%$ and $-10 \%$ did not make the project unfeasible, ensuring the return of the capital invested in the project, except when these are carried out simultaneously, rendering the results unfeasible. According to the conditions of the study concluded that the project is economically viable and the cultivation of cassava stands out as a good alternative in the practice of economic diversification in the production of the rural property.

\section{Revista Verde}

ISSN 1981-8203

Pombal, Paraíba, Brasil v. 14, n.1, jan.-mar, p.104-110, 2019

doi: $10.18378 /$ rvads.v14i1.5911 


\section{INTRODUÇÃO}

A mandioca (Manihot esculenta) também conhecida por aipim ou macaxeira, é uma Euphorbiaceae de origem Sul Americana bastante cultivada no passado pelos indígenas. Após a chegada dos portugueses e espanhóis, a cultura disseminou-se por outros continentes tornando-se um dos principais componentes da subsistência das populações de baixa renda, por se tratar de uma raiz rica em carboidrato e, também, de fácil produção devido à rusticidade (OTSUBO; LORENZI, 2004).

A produção de mandioca destaca-se no Brasil, principalmente para os agricultores familiares que são os principais responsáveis pela reposição do mercado alimentício interno, favorecendo a complementação da renda dessas famílias, principalmente por expor diversas formas de utilização e um amplo campo de comercialização. Isso ocorre em consequência da grande procura das pessoas por uma alimentação de qualidade (AMARO et al., 2007). Trata-se de uma cultura predominante no território nacional, que se encontra entre os primeiros produtos agrícolas brasileiros quando se considera a área cultivada (CARDOSO et al. 2014).

A raiz é consumida de diversas maneiras, exercendo papel importante na alimentação humana e animal, variando de acordo com os costumes das diferentes regiões, podendo ser comercializada de forma in natura, de mesa, ou, ainda, de forma industrializada, transformando-a principalmente em farinha ou até em matéria prima para outros subprodutos (ALMEIDA JÚNIOR et al., 2017). De acordo com Souza et al. (2014) a mandioca resiste às oscilações climáticas, o que torna possível o cultivo em regiões de baixa fertilidade com precipitação desuniforme, garantindo uma boa produtividade mesmo em pequenas áreas. $\mathrm{O}$ seu cultivo não se torna mais predominante devido à falta de inovações tecnológicas e informações agrícolas voltadas para o setor.

Em consequência de ser uma cultura nativa do Brasil, a produção de mandioca está distribuída em todo o território nacional, de acordo com o IBGE (2014), da seguinte forma: Nordeste $(24,4 \%)$, Norte $(34,6 \%)$, Sul $(24,0 \%)$, Sudeste $(10,9 \%)$ e Centro-Oeste $(6,1 \%)$. Em relação ao processamento de fécula, a região Centro-Oeste destaca-se com $25 \%$ da produção no território nacional, apesar de a região não representar tanta significância em relação à produção da raiz (EMBRAPA, 2017).

Sabendo-se que a distância entre o lucro e o prejuízo é cada vez menor, o conhecimento dos custos de produção é condição fundamental para a gestão da propriedade, uma vez que a mesma está inserida em mercado competitivo e dinâmico. Assim, a mensuração dos custos de produção nas atividades agrícolas deve se tornar rotina (RICHETTI et al., 2015). A mensuração deve ser realizada considerando que cada propriedade tem sua característica própria, o que pode levar a ocorrer alterações nos coeficientes técnicos utilizados (RICHETTI; SAGRILO, 2007).

Deste modo o uso de indicadores econômicos se torna indispensável para garantir a sustentabilidade do projeto, sendo uma ferramenta importante para a agricultura familiar, uma vez que pequenos produtores utilizam na maioria das vezes o conhecimento empírico para realizar suas atividades econômicas na propriedade (ALMEIDA et al., 2018). Diante do exposto, o objetivo deste trabalho foi realizar o levantamento dos custos de produção e determinar a viabilidade econômica da implantação da cultura da mandioca através de indicadores econômicos.

\section{MATERIAL E MÉTODOS}

O trabalho foi conduzido na fazenda experimental da Universidade Estadual de Goiás Campus Ipameri, situada no município de Ipameri-GO com 1743'19' de latitude sul e $48^{\circ} 09^{\prime} 35^{\prime \prime}$ de longitude oeste e altitude de $764 \mathrm{~m}$. O clima da região, segundo a classificação de Köppen é definido como tropical úmido, constando temperaturas elevadas com chuvas no verão e seca no inverno, apresentando temperatura média de $20^{\circ} \mathrm{C}$ (ALVARES et al., 2013).

A pesquisa foi realizada no período de janeiro a junho de 2018, em uma área de cinco hectares. Para a condução da cultura, procedeu-se a realização do preparo do solo, de modo a suprir as necessidades nutricionais, com a aplicação de adubação química e orgânica. Após a adubação realizou-se o processo de aração, com o intuito de descompactação e nivelamento, uma vez que para o bom desenvolvimento da raiz é necessário um solo descompactado.

No modelo do plantio proposto utilizou-se a cultivar BGMC 1086, também denominada por vassourinha branca, que se adapta melhor com a utilização do espaçamento de 1,0 $\mathrm{m}$ entre linhas por $0,8 \mathrm{~m}$ entre as plantas, com uma profundidade de semeadura de $0,15 \mathrm{~m}$ a $0,20 \mathrm{~m}$, cada maniva com dimensão aproximada de $0,20 \mathrm{~m}$ a $0,25 \mathrm{~m}$ de comprimento (ALMEIDA JUNIOR et al., 2017), a semeadura foi realizada manualmente com o auxílio de 10 pessoas por hectares.

Seguindo a metodologia proposta por Almeida Júnior et al., (2017), para o controle das ervas daninhas realizou-se uma aplicação de pré-emergente logo após o plantio. Posteriormente, com o intuito de realizar a manutenção da lavoura foram realizadas três capinas, sendo a primeira feita após 45 dias do plantio, e as demais realizadas com intervalos de 30 a 40 dias, entre cada uma. Antes da colheita foi realizada uma última limpeza na área, facilitando o processo de colheita. Este procedimento varia em um período de 7 a 8 meses após o plantio, e ocorre por meio do arranque das plantas, na qual as raízes são destacadas e acondicionadas em recipientes apropriados para o transporte.

Dentre os procedimentos utilizados para a obtenção dos dados foram realizadas entrevistas com o produtor rural, de modo a quantificar os processos realizados desde o preparo do solo até a colheita, tornando possível a realização do levantamento dos custos de produção em empresas locais (SILVA, 2006).

Os coeficientes técnicos propostos para a condução da cultura foram obtidos por meio de orientações advindas de entrevistas com empresas e produtores do setor, de modo a definir o sistema de manejo a ser utilizado, juntamente com a validação de pesquisadores da área de horticultura.

A estimativa dos custos de implantação adotou os seguintes itens: preparo do solo (horas de trator), plantio, insumos (adubos, defensivos e análise de solo), operações manuais (capinas, colheita), PRONAF custeio (2,5\%), fornecido pelo Banco do Brasil, oportunidade do uso da terra, que foi estimado de acordo com o valor médio praticado na região e outros custos, determinado por uma porcentagem sobre o custo operacional efetivo, de modo a suprir as necessidades de eventuais custos adicionais durante a condução do projeto. 
A condução do método de análise econômica iniciou-se por meio dos cálculos referentes ao fluxo de caixa, que segundo Erbano et al., (2014) se define como um controle de entrada e saída do capital, permitindo a análise de movimentação financeira de um determinado período.

$\mathrm{Na}$ estimativa dos custos de produção utilizou-se a metodologia de Custo Operacional Total (COT) que, de acordo com Matsunaga et al., (1976), é o somatório do Custo Operacional Efetivo (COE) e das demais despesas inclusas para a condução da cultura, as quais se aplicam uma porcentagem com outros custos, juros de custeio e custo com a oportunidade do uso da terra, demonstrando o custo total que pode ser desembolsado pelo produtor para a condução da cultura, enquanto o COE é constituído do somatório das despesas com operações manuais, operações mecanizadas, mão de obra e insumos utilizados pelo produtor durante a implantação da cultura (RAMBO et al., 2015).

De modo a complementar os resultados do trabalho, foram utilizados os seguintes indicadores econômicos: Receita Bruta (RB), Taxa Interna de Retorno (TIR), Valor Presente Líquido (VPL), Índice Beneficio/Custo (IBC) e Payback.

Receita bruta (RB): Trata-se da receita esperada para determinada produtividade, a um preço de venda (SOUZA et al., 2014). Para obter a receita foi estimada produtividade média de 23 toneladas.ha $^{-1}$, levando em consideração as características de manejo na região e o valor de produtividade à $\mathrm{R} \$ 450,00$ a tonelada, conforme o mercado local.

Taxa Interna de Retorno (TIR): É a taxa de desconto que iguala a receita esperada do empreendimento ao valor das futuras despesas, tornando o VPL igual a zero, calculado pela equação 1. (SIQUEIRA et al., 2011).

$0=\sum_{j=0}^{n} R_{j}+(l+i)^{j}-\sum_{j=0}^{n} C_{j}+(l+i)^{j}$

Valor Presente líquido (VPL): É um modelo matemático bastante utilizado para a análise de investimentos, calculado pela equação 2. O VPL determina a viabilidade de um cultivo pela diferença positiva entre benefícios e custos. Quando o VPL for superior ao valor do investimento, a atividade será desejável (RODRIGUES et al., 2007).

$\operatorname{VLP}=\sum_{j=0}^{n} R_{j}+(l+i)^{j}-\sum_{j=0}^{n} C_{j}+(l+i)^{j}$

Em que: $\mathrm{R}=$ lucros adquiridos no ano $\mathrm{j} ; \mathrm{C}=$ despesa do projeto no ano $\mathrm{j} ; \mathrm{n}=$ relação do total de tempo do projeto; VPL $>0=0$ projeto é viável economicamente (Receita $>$ Custo); VPL $<0=0$ projeto é inviável (Receita $<$ Custo); VPL $=0=$ Custo empatado com as despesas.

Índice Benefício/Custo (IBC) atualizado: Calculado pela equação 3, é uma medida de quanto se espera ganhar por unidade de capital investido. O IBC é uma razão entre o Fluxo Esperado de Benefícios de um projeto e o Fluxo Esperado de Investimentos necessários para realizá-lo (SOUZA; CLEMENTE, 2008).

Índice $\frac{B}{C}=\frac{\sum_{j=o}^{n} \frac{R_{j}}{(1+i)^{j}}}{\frac{\sum_{j=o}^{n} C_{j}}{(1+i)^{j}}}$

Em que: $\mathrm{Rj}=$ receitas adquiridas no ano $\mathrm{j}$; $\mathrm{I}=$ taxa de desconto; $\mathrm{C} \mathrm{j}=$ custo adquirido no ano; $\mathrm{n}=$ vida útil do projeto.

Payback atualizado: É um indicador que mostra quanto tempo o empréstimo ou investimento levará para retornar ao investidor ou à empresa, calculado pela equação 4 (VERGARA et al., 2017).

Payback atualizado $=\frac{\text { PVL (Investimentos) }}{\text { PVL (Lucros) }} \times 12$ meses

Após análise de viabilidade econômica efetuou-se uma análise de sensibilidade, que segundo Virgens et al., (2015) é uma forma de projetar possíveis cenários que possam contextualizar uma situação real, considerando variações na produção, preço e comercialização da cultura. No estudo em questão foram adotados os seguintes indicadores: VPL, IBC e Payback e considerou a simulação para cinco situações.

I Situação: Cenário real; II Situação: Aumento de 10\% nos custos; III Situação: Redução de $10 \%$ na produtividade; IV Situação: Redução de $10 \%$ no valor de comercialização; V Situação: Aumento de $10 \%$ nos custos, redução de $10 \%$ na produtividade e redução de $10 \%$ no valor de comercialização.

Os valores obtidos foram organizados em um banco de dados em Planilha Eletrônica do Microsoft Excel 2010 e a análise foi feita mediante estatísticas descritivas através da formulação de tabelas, permitindo assim, a discussão dos resultados. As análises foram realizadas para o período de cinco anos, utilizando a taxa de desconto de mercado em longo prazo, Taxa de Juros de Longo Prazo (TJLP), de 6,6\% ao ano (BNDES, 2018).

\section{RESULTADOS E DISCUSSÃO}

O custo operacional total para a produção de 115 toneladas de mandioca em cinco hectares resultou em $\mathrm{R} \$ 32.293,75$ (Tabela 1), totalizando o custo de $\mathrm{R} \$ 279,25$ para a cada tonelada produzida. No estudo realizado por Furlaneto et al. (2007), constatou-se custo por tonelada em $\mathrm{R} \$ 104,37$, valor $167,7 \%$ menor do que o encontrado no presente estudo, no entanto cabe ressaltar a diferença entre a época, os valores de mercado, a cultivar e manejo utilizada pelos autores. Outro fato importante que deve ser aferido é os gastos com fertilização e preparo do solo, como o presente estudo foi realizado em solo de Cerrado, naturalmente de baixa fertilidade e acidez, houve gastos com aquisição de fertilizantes, corretivos e práticas edáficas, uma vez que a cultura da mandioca é exigente em solos com alta fertilidade e principalmente ao nutriente fósforo como foi observado por Lima et al. (2018).

Tabela 1. Custo operacional da produção de mandioca, no município de Ipameri, Goiás

\begin{tabular}{lll}
\hline Descrição & $\begin{array}{l}\text { Valor } \\
\text { hectare }\end{array}$ & $\begin{array}{c}\text { por Valor para } \\
\text { hectares }\end{array}$ \\
\hline A - Operações manuais & & \\
\hline Corte das manivas & $\mathrm{R} \$ 80,00$ & $\mathrm{R} \$ 400,00$ \\
Plantio & $\mathrm{R} \$ 800,00$ & $\mathrm{R} \$ 4.000,00$ \\
Capina manual & $\mathrm{R} \$ 800,00$ & $\mathrm{R} \$ 4.000,00$ \\
Colheita & $\mathrm{R} \$ 1.600,00$ & $\mathrm{R} \$ 8.000,00$ \\
Total A & $\mathrm{R} \$ 3.280,00$ & $\mathrm{R} \$ 16.400,00$ \\
\hline
\end{tabular}

\begin{tabular}{lll}
\hline B - Operações Mecânicas & & \\
\hline Gradagem & $\mathrm{R} \$ 300,00$ & $\mathrm{R} \$ 1.500,00$ \\
Aplicação de corretivo & $\mathrm{R} \$ 50,00$ & $\mathrm{R} \$ 250,00$ \\
Total B & $\mathrm{R} \$ 350,00$ & $\mathrm{R} \$ 1.750,00$ \\
\hline C - Mão de obra & & \\
\hline Aplicação de corretivo & $\mathrm{R} \$ 40,00$ & $\mathrm{R} \$ 200,00$ \\
Gradagem & $\mathrm{R} \$ 40,00$ & $\mathrm{R} \$ 200,00$
\end{tabular}




\begin{tabular}{|c|c|c|}
\hline Total C & $\mathrm{R} \$ 80,00$ & $\mathrm{R} \$ 400,00$ \\
\hline \multicolumn{3}{|l|}{ D - Insumos } \\
\hline Análise de solo & $\mathrm{R} \$ 40,00$ & $\mathrm{R} \$ 200,00$ \\
\hline Super Simples & $\mathrm{R} \$ 300,00$ & $\mathrm{R} \$ 1.500,00$ \\
\hline Cama de frango & $\mathrm{R} \$ 900,00$ & $\mathrm{R} \$ 4.500,00$ \\
\hline Sencor & $\mathrm{R} \$ 70,00$ & $\mathrm{R} \$ 350,00$ \\
\hline $\begin{array}{l}\text { Pó seco (Controle } \\
\text { formiga) }\end{array}$ & de $\mathrm{R} \$ 10,00$ & $\mathrm{R} \$ 50,00$ \\
\hline Total D & $\mathrm{R} \$ 1.320,00$ & $\mathrm{R} \$ 6.600,00$ \\
\hline $\begin{array}{l}\text { Custo Operacional Efet } \\
\text { (COE) }\end{array}$ & tivo $\mathrm{R} \$ 5.030,00$ & $\mathrm{R} \$ 25.150,00$ \\
\hline Outros custos & $\mathrm{R} \$ 503,00$ & $\mathrm{R} \$ 2.515,00$ \\
\hline Juros de custeio & $\mathrm{R} \$ 125,75$ & $\mathrm{R} \$ 628,75$ \\
\hline $\begin{array}{l}\text { Custo de oportunidade } \\
\text { terra }\end{array}$ & da $\mathrm{R} \$ 800,00$ & $\mathrm{R} \$ 4.000,00$ \\
\hline $\begin{array}{ll}\begin{array}{l}\text { Custo } \\
\text { (COT) }\end{array} & \\
\end{array}$ & otal $\mathrm{R} \$ 6.458,75$ & $\mathrm{R} \$ 32.293,75$ \\
\hline
\end{tabular}

Os custos foram distribuídos em despesas com operações manuais representando $51,07 \%$ do COT, operações mecânicas com $5,45 \%$, mão de obra com $1,25 \%$, insumos com $20,05 \%$, destaque para os gastos de adubação química e orgânica representando em conjunto um total de 18,68\%, outros custos com $7,78 \%$, PRONAF custeio com $1,95 \%$ e a oportunidade da terra com $12,46 \%$ (figura 1).

Destaque para os valores encontrados em despesas com as operações manuais, em função de atividades como plantio, capina, corte das manivas e colheita, atividades que requer bastante investimento. Por outro lado, estas atividades proporcionam empregos para a região, em especial para agricultores familiares, visto que durante todo o manejo algumas atividades necessitam serem realizadas de forma manual, além do mais, esta prática favorece a permanência da família no campo, fato que nos últimos anos não tem sido percebido, onde os pequenos produtores estão migrando com seus filhos para as zonas urbanas em busca de oportunidade de empregos (ZARGO, 2016).

Figura 1. Participação representativa dos custos para a condução da cultura da mandioca em cinco hectares no município de Ipameri, Goiás.

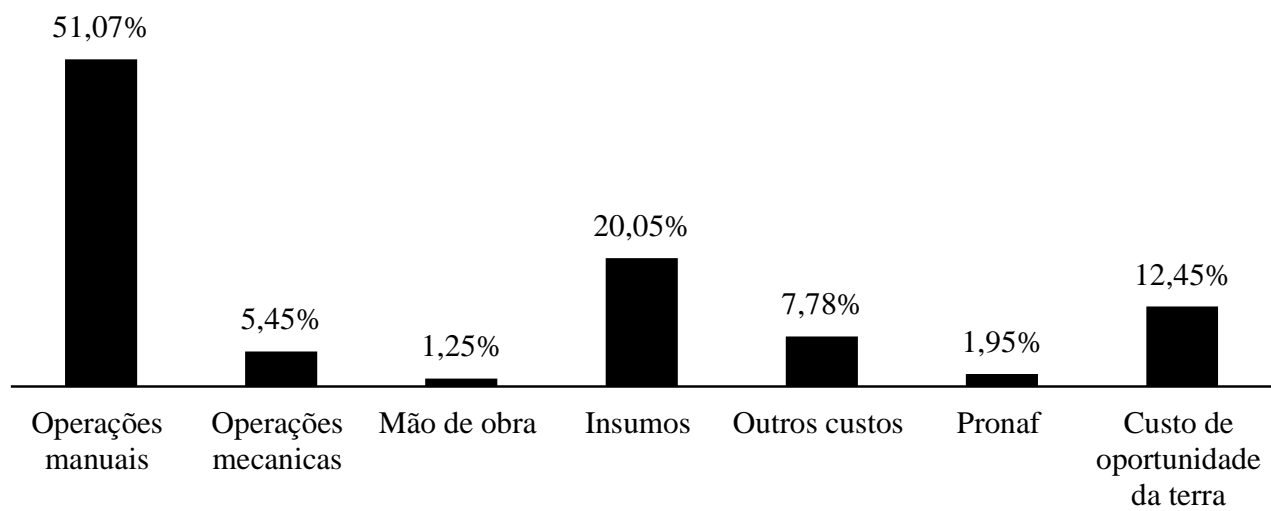

O estudo desenvolvido por Richetti (2007) demonstra que a condução da cultura destinada a indústria no estado de Mato Grosso do Sul, apresenta um percentual de custo com "operações de máquinas" e "mão-de-obra" representando mais de $50 \%$ do total, evidenciando que nas principais regiões produtoras do Brasil, os maiores custos de produção são referentes aos investimentos com o manejo da hortaliça, principalmente no controle de plantas daninhas, Furlaneto et al. (2007) afirmam que para atingir melhores produtividades, é necessário de duas a quatro capinas no estágio inicial de desenvolvimento (até 12 meses) e até mesmo o uso de herbicidas.

A lucratividade do produto in natura foi de $\mathrm{R} \$ 450,00$ a tonelada, tendo em vista que a produtividade média foi de 23 toneladas por hectare do cultivar BGMC 1086, gerando uma receita bruta por hectare de $\mathrm{R} \$ 10.350,00$, tendo em vista que todas as etapas de manejo para atingir esta boa produtividade foi adicionada aos cálculos, chegando a uma receita satisfatória para o mercado da região. No trabalho desenvolvido por Almeida Junior et al. (2017) utilizando a mesma cultivar, a receita bruta por hectare apresentada foi de $\mathrm{R} \$ 12.800,00$, uma vez que para a região de estudo o preço de comercialização da tonelada de mandioca encontrava-se superior ao valor descrito para a região do presente trabalho. A relação obtida entre os valores de receita e despesa são utilizadas para a obtenção do Valor Presente Líquido (VPL), utilizando taxa de $6,6 \%$ a.a. em horizonte de cinco anos para análise observa-se o fluxo de caixa na Tabela 2 .

Tabela 2. Fluxo de caixa da cultura da mandioca no município de Ipameri, Goiás.

\begin{tabular}{|c|c|c|c|c|c|c|}
\hline \multicolumn{4}{|c|}{1 hectare } & \multicolumn{3}{|c|}{5 hectare } \\
\hline Anos & $\begin{array}{c}\text { Receita } \\
\text { atualizada }(\mathrm{R} \$)\end{array}$ & $\begin{array}{c}\text { Despesa } \\
\text { atualizada }(\mathrm{R} \$)\end{array}$ & $\begin{array}{l}\text { Fluxo de caixa } \\
\text { atualizado }(\mathrm{R} \$)\end{array}$ & $\begin{array}{l}\text { Receita atualizada } \\
(\mathrm{R} \$)\end{array}$ & $\begin{array}{c}\text { Despesa } \\
\text { atualizada }(\mathrm{R} \$)\end{array}$ & $\begin{array}{l}\text { Fluxo de caixa } \\
\text { atualizado }(\mathrm{R} \$)\end{array}$ \\
\hline 0 & & $(6.458,75)$ & $(6.458,75)$ & & $(32.113,75)$ & $(32.113,75)$ \\
\hline 1 & $9.709,19$ & $6.058,86$ & $3.650,33$ & $48.545,97$ & $30.125,47$ & $18.420,50$ \\
\hline 2 & $9.108,06$ & $5.683,74$ & $3.424,32$ & $45.540,31$ & $28.260,29$ & $17.280,02$ \\
\hline 3 & $8.544,15$ & $5.331,84$ & $3.212,31$ & $42.720,74$ & $26.510,59$ & $16.210,15$ \\
\hline 4 & $8.015,15$ & $5.001,72$ & $3.013,42$ & $40.075,74$ & $24.869,22$ & $15.206,52$ \\
\hline 5 & $7.518,90$ & $4.692,05$ & $2.826,85$ & $37.594,50$ & $23.329,48$ & $14.265,02$ \\
\hline Total & $36.436,70$ & $26.768,21$ & $9.668,49$ & $182.363,50$ & $133.095,05$ & $49.268,45$ \\
\hline
\end{tabular}


A produção de mandioca in natura apresentou VPL igual à $\mathrm{R} \$ 49.268,45$, enquanto que a produção de fécula no trabalho descrito por Schrippe et al. (2012), obteve um VPL negativo de $\mathrm{R} \$$ - $16.145,27$. Isso ocorreu devido à maior exigência de maquinários com maior tecnologia e mão de obra para a produção de fécula, enquanto que no presente trabalho a mão de obra necessária é para os processos de preparo das manivas, manutenção com as capinas, controle de pragas com a aplicação de defensivos químicos por bomba costal e a colheita, constatando menor investimento quando comparado à produção de fécula.

Diante dos estudos levantados, os indicadores de rentabilidade da cultura da mandioca expressam a viabilidade da implantação da mesma. Os resultados dos indicadores econômicos possibilitaram aferir que o presente projeto é uma cultura promissora para o agronegócio brasileiro e uma alternativa de produção para agricultores familiares, principalmente para região do sudeste goiano. Na prática o uso de indicadores econômicos na agricultura familiar é muito deficiente, assim a maioria dos produtores rurais desconhece o retorno econômico de seus projetos (ALMEIDA et al., 2018).

É possível observar que para o TIR, o resultado foi de $45 \%$, e para o IBC, o valor obtido foi de 1,37 , demonstrando que as somas das receitas foram superiores às despesas, assim a cada real investido obteve-se 37 centavos de lucro (Tabela 3). Nas pesquisas realizadas por Souza et al. (2014) com mais de uma cultivar de mandioca implantada em 1 ha, obteve-se uma variação entre os resultados das diferentes cultivares, oscilando entre 2,02 a 3,18, demonstrando que a mandioca é uma cultura que apresenta baixos custos para a implantação e que sua receita se mostra superior aos custos logo no primeiro ciclo da cultura. O payback calculado foi de dois anos, o que significa que essa é uma cultura que apresenta um tempo de retorno do investimento rápido, enquanto que para o trabalho realizado por Schrippe et al. (2012), o período de retorno foi maior, tendo em vista o seu maior custo com mão de obra para o preparo da fécula e o maior tempo de produção.

Tabela 3. Indicadores de avaliação econômica para a implantação da mandioca no município de Ipameri, Goiás.

\begin{tabular}{cccc}
\hline \multicolumn{3}{c}{ Indicadores econômicos } \\
\hline & 1 hectare & \multicolumn{2}{c}{5 hectares } \\
\hline VPL & R $\$ 9.668,49$ & VPL & R $\$ 49.268,45$ \\
BC & 1,36 & BC & 1,37 \\
Payback & 2 anos & Payback & 2 anos \\
TIR & $44 \%$ & TIR & $45 \%$ \\
\hline
\end{tabular}

De acordo com a análise de sensibilidade (Tabela 4), a situação I resultou em melhores resultados nos indicadores em comparação às demais situações avaliadas, mostrando que mesmo ocorrendo possíveis aumentos de custo, a atividade ainda consegue ser rentável. As situações II e III também apresentaram viabilidade, mesmo ocorrendo redução na produtividade e no valor de comercialização, respectivamente. Nestes casos os indicadores econômicos permaneceram os mesmos. E ao analisar a situação IV é possível identificar que o projeto não apresentaria viabilidade, visto que foi descrito o pior cenário para o empreendimento com aumento dos custos, redução na produtividade e comercialização.
A análise de sensibilidade foi procedida a fim de observar o efeito da viabilidade do cultivo de mandioca à frente de situações inesperadas do mercado e de produtividade. Outros autores também utilizaram a análise de sensibilidade como Benter Gama et al. (2005) que simulou variações de $\pm 20 \%$ das receitas e custos para avaliar o efeito sobre os rendimentos, partindo de procedimentos computacionais para obtenção das simulações. Do mesmo modo, Peres et al. (2009) em sistemas de produção de leite em pastagem utilizaram a análise de sensibilidade para simular situação de risco, proporcionando informações importantes para a tomada de decisão dos produtores.

Cabe ressaltar que, antes do produtor escolher com qual cultura implantar é importante que avalie suas condições orçamentárias, bem como pontos fortes e pontos fracos de sua propriedade. Outro fato importante citado por Peres et al. (2009) é a possibilidade do agricultor familiar aliar-se aos vizinhos para aumento na escala de produção ou até mesmo associarem a uma cooperativa, garantindo assim maior longevidade e eficiência na produção.

Tabela 4. Análise de sensibilidade dos indicadores econômicos em 5ha, no município de Ipameri, Goiás

\begin{tabular}{cccc}
\hline Situações & VPL $(\mathrm{R} \$)$ & BC & Payback \\
\hline I & $49.268,45$ & 1,37 & 2 anos \\
II & $32.747,57$ & 1,22 & 3 anos \\
III & $27.820,73$ & 1,21 & 3 anos \\
IV & $27.820,73$ & 1,21 & 3 anos \\
V & $8.003,11$ & 0,95 & $*$ \\
\hline
\end{tabular}

Notas: I Situação: Cenário real; II Situação: Aumento de 10\% nos custos; III Situação: Redução de $10 \%$ na produtividade; IV Situação: Redução de $10 \%$ no valor de comercialização; V Situação: Aumento de $10 \%$ nos custos, redução de $10 \%$ na produtividade e redução de $10 \%$ no valor de comercialização; *: Durante os cinco anos de análise não obteve retorno do investimento.

De maneira geral, é importante salientar que cada propriedade possui características específicas, desde a qualidade do solo, oferta de mão de obra, proximidade de mercado, etc., portanto as estimativas poderão variar conforme cada localidade. Assim, torna-se cada vez mais importante a realização de pesquisas referentes à análise econômica com abrangência regional, antes da implantação das culturas, tornando uma ferramenta indispensável para os produtores, que irá transmitir maior segurança durante a implantação do empreendimento. Por fim, vale ressaltar também que, os produtores da região de Ipameri, Goiás possuem aspectos favoráveis para a implantação da cultura da mandioca.

\section{CONCLUSÃO}

A implantação do cultivo de mandioca tem baixo custo, demonstrando viabilidade econômica do cultivo para as condições edafoclimáticas da região de Goiás.

A cultura da mandioca é uma boa alternativa para diversificação da produção na propriedade rural por gerar opções de fontes de renda para produtores rurais.

\section{AGRADECIMENTOS}

À Universidade Estadual de Goiás e o Instituto para o Fortalecimento da Agropecuária de Goiás - IFAG pela parceria e suporte à pesquisa. 


\section{REFERÊNCIAS}

ALMEIDA JÚNIOR, J. J.; SANTOS, G. A.; PEROZINE, A C.; MATOS, F. S. A.; SMILJANIC, K. B. A.; MARTINS FILHO, M. B. Custo de implantação da cultura da mandioca (Manihot esculenta, L), no Sudoeste goiano, município de Mineiros estado de Goiás. In: I Colóquio Estadual de Pesquisa Multidisciplinar, Mineiros, 2017.

ALMEIDA, L. S.; SANTOS, A. C. G. P.; HOLANDA, L. R. Análise de viabilidade econômica de um pequeno produtor de maracujá em boca da mata, alagoas. Sistemas \& Gestão, v. 13, n. 1, p. 357-365, 2018.

ALVARES, C. A.; STAPE, J. L.; SENTELHAS, P.C.; GONÇALVES, J.L.M.; SPAROVEK, G. Köppen's climate classification map for Brazil. Meteorologische Zeitschrift, v. 22, n. 6, p. 711-728, 2013.

AMARO, G. B.; SILVA, D. M.; MARINHO, A. G.; NASCIMENTO, W. M. Recomendações técnicas para o cultivo de hortaliças em agricultura familiar. Embrapa. Brasília, 2007.

BANCO DO BRASIL. Crédito Rural Pronaf Custeio. Disponível em: <http://www.bb.com.br/pbb/paginainicial/agronegocios/agronegocio---produtos-eservicos/credito/credito-para-custeio/pronaf-custeio\#/>. Acesso em: 20 de maio de 2018.

BENTES-GAMA, M. M. SILVA, M. L.; VILCAHUAMAN, L. J. M.; LOCATELLI, M. Análise econômica de sistemas agroflorestais na Amazônia Ocidental, Machadinho D’OesteRO. Revista Árvore, v. 29, n. 3, p. 401-411, 2005. 10.1590/S0100-67622005000300007.

BNDES, Banco Nacional de Desenvolvimento Econômico e Social. Brasília: BNDES. Taxa de Juros de Longo Prazo, 2018. Disponível em <https://www.bndes.gov.br/wps/portal/site/home/financiamen to/guia/custos-financeiros/taxa-de-juros-de-longo-prazo-tjlp.> Acesso em: 22 de mar. 2018.

CARDOSO, A. D.; VIANA, A. E. S.; MUNIZ, W. F.; ANDRADE, J. S.; MOREIRA, G. L. P.; CARDOSO JÚNIOR, N. S. Avaliação de variedades de mandioca tipo indústria. Magistra, v. 26, n. 4, p. 456-466, 2014.

CARVALHO, L. C.; ESPERANCINI, M. S. T.; SANTOS, J. Z.; RIBAS, L. C. Análise comparativa de estimativas de custo de produção e rentabilidade entre soja RR1 e RR2 PRO/Bt ${ }^{1}$. Energia na agricultura, v. 31, n. 2, p. 186-191, 2016. 10.17224/EnergAgric.2016v31n2p186-191.

ERBANO, B. L; THEISEN, D. G.; VEBER, E. E.; SOUZA, M. E. S.; SOUZA, A.; APEL, R. Fluxo de caixa. Maiêutica Estudos Contemporâneos em gestão organizacional, v. 1, n 1, p. 131-134. 2014.

FURLANETO, F. P. B; KANTHACK, R. A.; ESPERANCINI, M. S. T. Análise econômica da cultura da mandioca no Médio Paranapanema, estado de São Paulo. Informações Econômicas, v. 37, n. 10, p. 1-12, 2007.
IBGE. PAM. Produção agrícola municipal 2014. Disponível em: 〈http://ibge.gov.br〉. Acesso em: 11 de abril de 2018.

LIMA, A. G.; CARVALHO, L. R.; MOTA, M. C.; LIMA JUNIOR, A. F.; MOREIRA, J. M.; SILVA, A. P.; BARBUIO, R.; ROSA, J. Q. S. Produtividade de mandioca avaliada sobre adubação fosfatada e a adubação de cobertura. $\begin{array}{llllll}\text { Pubvet, } & \text { v. } 12, \quad \text { n. } & \text { 8, } & \text { p.1-4, }\end{array}$ 10.31533/pubvet.v12n8a151.1-4

MARTIN, N. B.; SERRA, R.; OLIVEIRA, M. D. M.; ÂNGELO, J. A.; OKAWA, H. Sistema de custos agropecuários - CUSTAGRI. Informações Econômicas, v. 28, n. 1, p. 7-28, 1998.

OTSUBO, A. A.; LORENZI, J. O. Cultivo da Mandioca na Região Centro-Sul do Brasil. Embrapa. Março, 2004.

PERES, A. A. C.; VÁSQUEZ, H. M.; SOUZA, P. M.; SILVA, J. F. C.; VILLELA, O. V.; SANTOS, F. C. Análise financeira e de sensibilidade de sistemas de produção de leite em pastagem. Revista Brasileira de Zootecnia, v. 38, n. 10, 2009. 10.1590/S1516-35982009001000030

RAMBO, J. R.; TARSITANO, M. A. A.; KRAUSE, W.; LAFORGA, G.; SILVA, C. Análise financeira e custo de produção de banana-maçã: um estudo de caso em Tangará da Serra, Estado do Mato Grosso. Informações econômicas, v.45, n. 5, p. 29-39, 2015.

RICHETTI, A. Estimativa de produção de mandioca industrial, safra 2007. Comunicado Técnico 133. Dourados: EMBRAPA, maio 2007. 6 p.

RICHETTI, A.; FLUMIGNAN, D. L.; ALMEIDA, A. C. S. Viabilidade Econômica do Milho Safrinha, Sequeiro e Irrigado, na Região Sul de Mato Grosso do Sul: Embrapa Agropecuária. 2015, 13p. (Comunicado técnico 207).

RODRIGUES, E. R.; CULLEN JÚNIOR, L.; BELTRAME, T. P.; MOSCOGliATO, A. V.; SILVA, I. C. Avaliação econômica de sistemas agroflorestais implantados para recuperação de reserva legal no pontal do Paranapanema, São Paulo. Revista Árvore, v. 31, n. 5, p. 941-948, 2007.

ROVER, S.; OLIVEIRA, J. L. B.; NAGAOKA, M. P. T. Viabilidade Econômica da implantação de um sistema de cultivo de alface hidropônica no município de Tijucas - Santa Catarina. Revista de Ciências Agroveterinárias. v. 15, n. 3, p. 169-179, 2016. 10.5965/223811711532016169.

SCHRIPPE, P.; BORTOLOTTI，S. L. V.; POSSAN, E. Estudo da viabilidade técnico-econômica da recuperação de fécula em uma fecularia de mandioca. In: XXXII ENCONTRO NACIONAL DE ENGENHARIA DE PRODUÇÃO. Bento Gonçalves, RS. 2012. Disponível em: <http://www.abepro.org.br/biblioteca/ENEGEP2012_TN_ST O_157_913_19868.pdf>. Acesso em: 23 de set. 2017.

SIQUEIRA, H. M.; SOUZA, P. M.; PONCIANO, N. J. Café convencional versus café orgânico: perspectivas de sustentabilidade socioeconômica dos agricultores familiares 
do Espírito Santo. Revista Ceres, v. 58, n. 2, p. 155-160, 2011.

SOUZA, A.; CLEMENTE, A. Decisões Financeiras e Análise de Investimentos. 6a . Ed., São Paulo, Ed. Atlas, 2008.

SOUZA, R. F.; SILVA, I. F.; SILVEIRA, F. P. M.; NETO, M. A. D.; ROCHA, I. T. M. Analise econômica no cultivo da mandioca. Revista Verde de Agroecologia e Desenvolvimento Sustentável, v. 9, n. 2, p. 345-354, 2014.

VERGARA, W. R. H.; OLIVEIRA, J. P. C.; BARBOSA, F. A.; YAMANARI, J. S. Análise de viabilidade econômicofinanceira para aquisição de uma unidade de armazenagem de soja e milho. Gestão da Produção, Operações e Sistemas, v 12, n 1, p. 41-61, 2017.

VIRGENS, A. P.; FREITAS, L. C.; LUZ, D. S.; MOREIRA, A. C. D. Análise econômica e de sensibilidade em projetos de reflorestamentos no estado da Bahia. Enciclopédia Biosfera, v. 11, n. 21, p. 120-127, 2015.

ZARGO, N. Migração rural-urbana, juventude e ensino superior. Revista Brasileira de Educação, v. 21, n. 64, p. 1-19, 2016. 